This item was submitted to Loughborough's Research Repository by the author.

Items in Figshare are protected by copyright, with all rights reserved, unless otherwise indicated.

\title{
Study on the appropriate dimensions and position of slots and notches in the ground plane of planar monopole handset antenna for bandwidth enhancement
}

\section{PLEASE CITE THE PUBLISHED VERSION}

http://dx.doi.org/10.1109/APWC.2013.6624868

PUBLISHER

(C) IEEE

VERSION

AM (Accepted Manuscript)

\section{PUBLISHER STATEMENT}

(C) 2013 IEEE. Personal use of this material is permitted. Permission from IEEE must be obtained for all other uses, in any current or future media, including reprinting/republishing this material for advertising or promotional purposes, creating new collective works, for resale or redistribution to servers or lists, or reuse of any copyrighted component of this work in other works.

\section{LICENCE}

All Rights Reserved

\section{REPOSITORY RECORD}

Saraereh, Omar A., Chinthana Panagamuwa, J. C. Vardaxoglou, and Qais H. Alsafasfeh. 2019. "Study on the Appropriate Dimensions and Position of Slots and Notches in the Ground Plane of Planar Monopole Handset Antenna for Bandwidth Enhancement". figshare. https://hdl.handle.net/2134/25907. 


\title{
Study on the Appropriate Dimensions and Position of Slots and Notches in the Ground Plane of Planar Monopole Handset Antenna for Bandwidth Enhancement
}

\author{
Omar A. Saraereh $^{1} \quad$ C. J. Panagamuwa ${ }^{2}$ and J. C. Vardaxoglou ${ }^{2} \quad$ Qais H. Alsafasfeh $^{3}$
}

\begin{abstract}
A slotted ground plane structure combined with a multiband planar monopole handset antenna for bandwidth enhancement and resonant modes tuning is presented. By simply inserting intelligent modifications using slots and notches to the system ground plane of an internal multiband handset antenna, a significant improvement in the bandwidths of lower bands LTE 700/GSM 850/GSM 900 and upper bands GSM 1800/1900, UMTS, LTE 2300/2500, WiMAX 3500, WLAN 2400/5200/5800 is achieved. The influences of the proposed slots and notches with different positions and dimensions on antenna performance are analyzed by means of simulations and parametric studies. Results show that the proposed ground plane modifications have improved the handset antenna performance to cover 12-band standard operations successfully.
\end{abstract}

\section{INTRODUCTION}

One of the critical challenges in mobile phone antenna design is the limited volume allocated for antenna element integration and system ground plane length. Recently, handset dimensions have been enlarged to accommodate many attractive features for consumers. The features include large color screens, cameras, music players and multimedia broadcast receivers. In addition, mobile communication devices are required to adopt numerous new cellular and wireless services. Therefore, these devices must be able to operate in multi-frequency wide bands with physically small internal multiband antenna.

It is a common practice for antenna designers to optimize the antenna geometry to obtain an adequate performance, but as it has been shown in [1-4], the ground plane of the handset also plays a vital role in the antenna system performance. This is because the system ground itself may act as a radiating element. The optimum ground plane length which efficiently excites the ground plane mode and maximizes antenna bandwidth at low frequencies is quite large [4]. This length is approximately $0.43 \lambda$ and at the Long Term Evolution (LTE) $700 \mathrm{MHz}$ frequency band this corresponds to a length not less than 180 $\mathrm{mm}$. This length is too long to integrate into new mobile phones and consequently other solutions or techniques are necessary to cover new communication bands and bandwidth requirements. The bandwidth enhancement approaches mentioned in literature focus mainly on making modifications on the antenna's radiating element. An alternate method for achieving bandwidth enhancement is to alter the system ground plane itself. Ground plane current distribution can be perturbed [4-6] by inserting intelligent slots and notches which efficiently provoke ground plane radiation and improve antenna performance. This study demonstrates the use of slots and notches in the ground plane to produce multiband operation with wideband characteristics. The antenna used for this purpose is a planar printed monopole antenna which combines a coupled-fed radiating element with a meandered shorted coupling strip. The proposed ground plane modifications effectively adjust the electrical lengths of the ground plane to the optimal lengths required by the low, middle and high frequency bands. The final antenna design has four wide operating bands that effectively cover twelve communication standards at LTE 700/2300/2500, GSM 850/900/1800/1900, UMTS, WiMAX 3500 and WLAN 2400/5200/5800. The simulated results of return loss, radiation patterns and surface currents are presented and discussed. The proposed design is suitable to be integrated in smart phones.

The different slots introduced into the system ground plane structure contribute their lowest, middle and higher-order resonant modes to form four wide operating bandwidths (return loss $>6 \mathrm{~dB}$ ). By parametric studies via simulations using CST MWS $^{\mathrm{TM}}$, varying the location and size of these slots and notches result in a novel procedure for bandwidth enhancement using system ground plane.

\section{GROUND PLANE DESIGN AND RESULTS ANALYSIS}

The configuration of the proposed slotted ground plane combined with a planar monopole antenna is depicted in Figure 1. The planar printed coupled-fed monopole has been developed within the top area of the printed circuit board (PCB) to occupy an area of $17 \times 50 \mathrm{~mm}^{2}$. The PCB is a $0.8 \mathrm{~mm}$ thick FR-4 substrate (relative permittivity 4.4 and loss tangent is 0.02 ) of total size $50 \times 120 \mathrm{~mm}^{2}$ and is comparable in size to recent smart phones. The system ground plane of size $50 \times 105.4 \mathrm{~mm}^{2}$ is printed on the back side of the $\mathrm{PCB}$, leaving a no-ground portion of a size $14.6 \times 50 \mathrm{~mm}^{2}$ in the top region as depicted in Figure 1. A $50 \Omega$ port to excite the antenna and a shorting pin (via) is connected between the shorted coupling strip and the slotted ground plane. A detailed analysis of the planar monopole antenna located in the no-

\footnotetext{
${ }^{1}$ Department of Electrical Engineering, The Hashemite University, Zarqa 13115, Jordan, e-mail: eloas2@hu.edu.jo, tel.: +962 53903333.

${ }^{2}$ Centre for Mobile Communications Research, Loughborough University, Loughborough, LEICS., LE11 3TU, UK. e-mail: C.J.Panagamuwa@lboro.ac.uk.

${ }^{3}$ Department of Electrical Engineering, Tafila Technical University, Tafila 66110, Jordan, e-mail: qshashim@yahoo.com.
} 
ground area is not the focus of this paper. Instead the authors concentrate on the broadbanding techniques employed. In order to broaden the bandwidth of the antenna, different slots $\mathrm{S}_{1}, \mathrm{~S}_{2}$, and $\mathrm{S}_{3}$ and notches $\mathrm{n}_{1}$, and $\mathrm{n}_{2}$ have been introduced into the system ground plane as shown in Figure 1. They are purposefully added away from battery, displays, speakers and other components that can weaken the slots and notches effects.

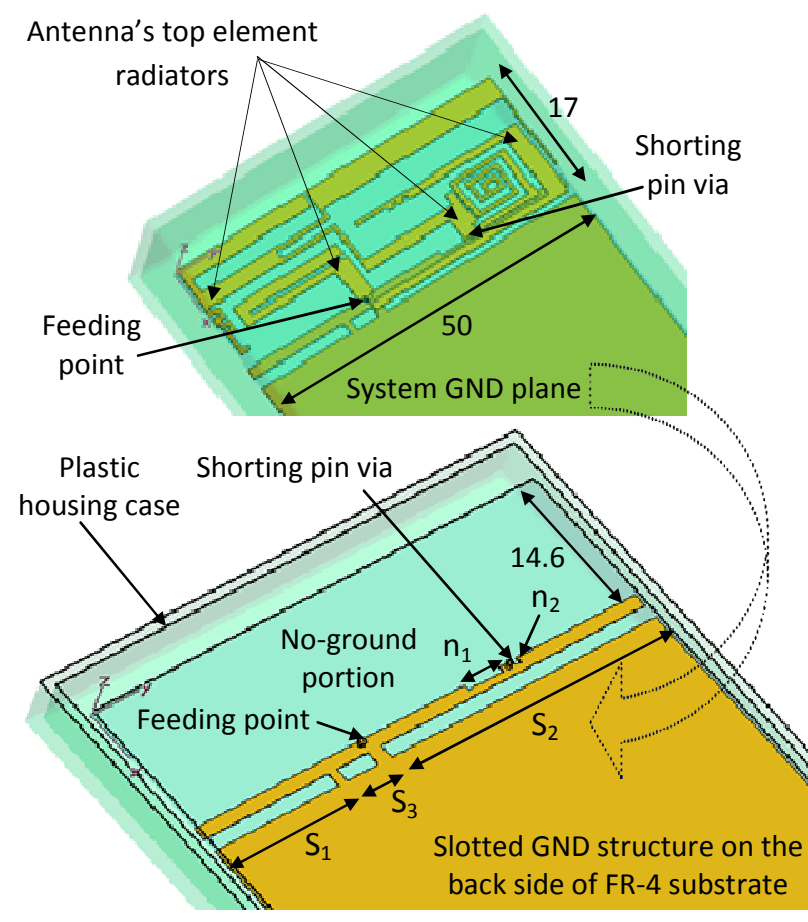

Figure 1: Planar monopole antenna with proposed slotted ground plane structure configuration.

The plastic housing cover is also considered for the real mobile terminal circumstances. The plastic material utilized is ABS polymer (relative permittivity is 3.3 and loss tangent 0.02). The housing cover has dimensions of $54 \times 130 \mathrm{~mm}^{2}$ with $1 \mathrm{~mm}$ thickness. It has also a $3 \mathrm{~mm}$ gap between the antenna and the inner housing cover. The selected dimensions allow the system circuit board to be at the center of the plastic housing.

For comparison, the design without any modifications on the system ground plane is used as a reference design (denoted as REF) with a $\mathrm{S}_{11}$ shown in Figure 2. The REF design has three frequency bands at $-6 \mathrm{~dB} \mathrm{~S}_{11}$ with resonances $0.835 \mathrm{GHz}, 2.367$ $\mathrm{GHz}$ and poorly matched at $4.785 \mathrm{GHz}$. The first band needs to be tuned and shifted to cover low frequency bands such as LTE 700 and GSM 850/900. The second band needs to be broadened to cover at least GSM 1800/1900, UMTS, LTE 2300/2500, WLAN 2400 and WiMAX3500 operations. The third band needs to be shifted to cover upper frequencies such as WLAN5200/5800. In order to achieve the aforementioned operations two notches $\mathrm{n}_{1}$ $\left(4 \times 0.5 \mathrm{~mm}^{2}\right)$ and $\mathrm{n}_{2}\left(0.5 \times 0.5 \mathrm{~mm}^{2}\right)$ have been cut in the ground plane adjacent to the critical area around the shorting pin to disturb surface currents. It is clear from Figure 2 the two notches have minimal effect on the impedance bandwidth and resonances of the achieved frequency bands. Therefore, to give more flexibility for parametric studies, three slots $S_{1}$, $\mathrm{S}_{2}$ and $\mathrm{S}_{3}$ of $1 \mathrm{~mm}$ fixed width and different lengths have been etched into the ground plane underneath the lower edge of the main antenna elements as depicted in Figure 1. Effect of the location of each slot and the three slots in series together has been investigated to reach an optimum antenna performance with the aid of ground plane system electrical surface currents. Figure 2 shows that inserting the three slots into the ground plane without any notches has significantly improved the impedance bandwidth of exiting bands to establish four operating frequency bands. The results show that the obtained frequency bands resonate at $730 \mathrm{MHz}$ (bandwidth $368 \mathrm{MHz}$; 43\%), $2380 \mathrm{MHz}$ (bandwidth $1040 \mathrm{MHz}$; 47\%), $3485 \mathrm{MHz}$ (bandwidth $190 \mathrm{MHz}$; $5.2 \%$ ) and $5450 \mathrm{MHz}$ (bandwidth $719 \mathrm{MHz} ; 14 \%$ ) respectively. The final modification for the proposed design is combining both slots and notches at the same time which improved the third band to resonate at $3475 \mathrm{MHz}$ (bandwidth $220 \mathrm{MHz} ; 8.2 \%$ ). It can be noted in Figure 2 that the final design simulated bandwidth (for $S_{11} \leq-6 \mathrm{~dB}$ ) has four operating wide bands. The first operating band $(694-107 \mathrm{MHz})$ is able to cover the LTE 700 and GSM 850/900 operations, while the second operating band (1707$2737 \mathrm{MHz}$ ) allows GSM 1800/1900, UMTS, LTE 2300/2500 and WLAN 2400 operations. The third operating band (3363-3614 MHz) covers WiMAX 3500 and finally the highest operating band (5096$5819 \mathrm{MHz}$ ) covers WLAN 5200/5800.

In order to understand the behavior of the modifications introduced to the system ground plane, the effect of varying the location of the three series slots $\left(S_{1}, S_{2}\right.$ and $\left.S_{3}\right)$ all together on the impedance bandwidth has been parametrically studied. The location of the slots all together has been varied with $20 \mathrm{~mm}$ step away from main radiating antenna element. Figure 3 shows the influences of varying the slots location on antenna bandwidths compared to the proposed design. It can be seen from Figure 3 that, when the location of the three slots altogether varied from $20 \mathrm{~mm}$ to $100 \mathrm{~mm}$, the antenna bandwidth of band 1, band 2 and band 4 has been degraded significantly while band 3 has been lacerated since it separates to two small bands. To show the effect of varying the location of one of the slots without touching the others, Figure 4 shows the effect of varying the location of slot $\mathrm{S}_{2}$ on impedance bandwidth with $20 \mathrm{~mm}$ step away from the main antenna element. It can be noted that the impedance 
bandwidth of band 1 and band 4 significantly has been reduced to stop operating at GSM 850/900 and WLAN 5200. Band 2 and band 3 have been separated to two resonant modes each and impedance bandwidth slightly degraded to stop operating at GSM 1800/1900 in band 2 and WiMAX 3500 in band 3 .

The previous parametric studies and other studies during this work indicate that the optimal performances of the obtained bands are highly depending on the slots location. Other parametric studies such as the slots and notches dimensions have been carried out and revealed the strong effect on the entire design performance. A rigorous analysis has been carried out in order to establish the dimensions and position of slots $\left(\mathrm{S}_{1}, \mathrm{~S}_{2}\right.$, and $\left.\mathrm{S}_{3}\right)$ and the two notches $\left(\mathrm{n}_{1}, \mathrm{n}_{2}\right)$ in the ground plane. Table 1 shows the optimum values for the proposed ground plane design parameters. Slot $\mathrm{S}_{1}$ has been designed to improve the impedance bandwidth in the high frequency region resonating at $3500 \mathrm{MHz}$ to form two adjacent resonances at $3420 \mathrm{MHz}$ and $3552 \mathrm{MHz}$ with an optimum length of approximately quarter $\lambda$. Slot $S_{2}$ is designed to be longer than $S_{1}$ and the best position for this slot is obtained when it is located in series with $\mathrm{S}_{1}$ as shown Figure 1. The reason for choosing this position is due to the fact that it is the location where the ground plane presents high current values and its current can be easily modified. The slot with an optimum size couples with the shorted part of the main antenna element to achieve an effective electrical length of $0.2 \lambda$ at $740 \mathrm{MHz}, 0.27 \lambda$ at 1051 $\mathrm{MHz}, 0.47 \lambda$ at $1780 \mathrm{MHz}$ and greater than half wavelength for the upper bands at $3500 \mathrm{MHz}$ and $5500 \mathrm{MHz}$.

A third shorter slot $\mathrm{S}_{3}$ has been inserted between $S_{1}$ and $S_{2}$ into the ground plane with two notches etched very close to the shorting pin via to shift the lower band to resonate at $720 \mathrm{MHz}$ and cover the desired lower band (695-1068 MHz) denoted as band 1. Figure 5(a) and (b) shows the surface current distributions for the design without any modifications in ground plane compared to the proposed one with slots and notches at $715 \mathrm{MHz}$. It can be seen that there is a significant difference in the current distributions. In case (a), a little portion of the antenna element is radiating with weak coupling to the ground. However, in case (b) it is very clear that the currents flow around the ground slots, the strip between feeding point and shorting point above the slotted area and the entire ground plane at the edges particularly to build up strong coupling. This way, the effective electrical length is larger and will be able to reach optimum value to broaden the impedance bandwidth. Figure 6 shows a sample of radiation patterns at $715 \mathrm{MHz}$ for proposed design.

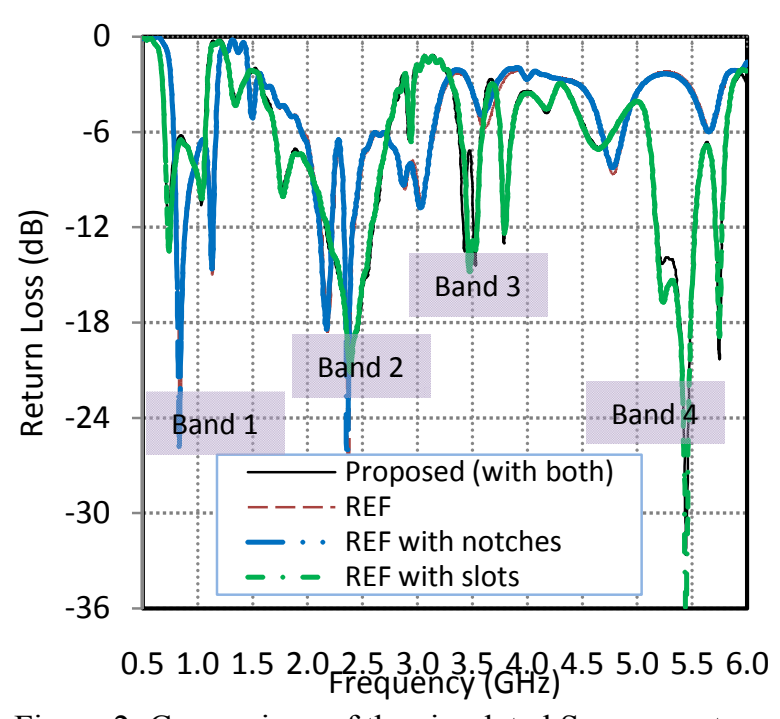

Figure 2: Comparison of the simulated $S_{11}$ parameters for the proposed design, REF design, REF design with notches alone and REF design with slots alone.

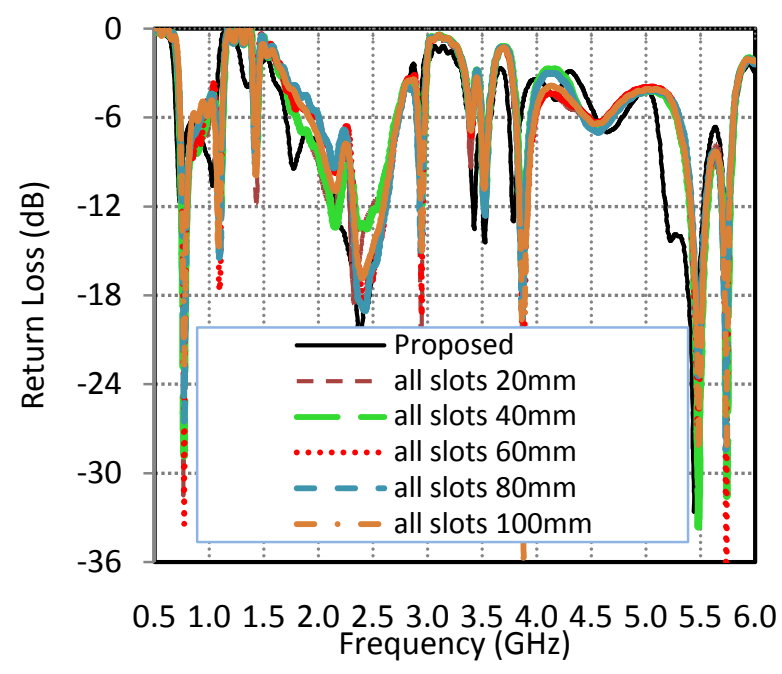

Figure 3: Effect of varying the location of slots $\left(\mathrm{S}_{1}, \mathrm{~S}_{2}\right.$ and $S_{3}$ ) all together on impedance bandwidth with $20 \mathrm{~mm}$ step.

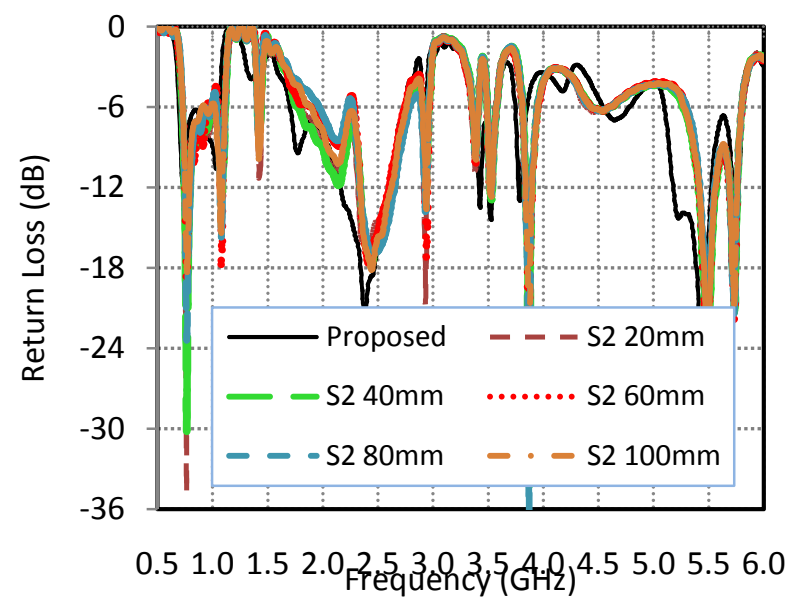

Figure 4: The effect of varying the location of slot $\mathrm{S}_{2}$ alone on impedance bandwidth with $20 \mathrm{~mm}$ step. 
The patterns do not change significantly due to the introduced modifications and similar to dipole antenna radiation characteristics (omnidirectional in $=0^{\circ}$ ).

\begin{tabular}{|c|c|}
\hline Parameter & Value (length $\times$ width) \\
\hline$S_{1}$ & $14 \times 1 \mathrm{~mm}$ \\
\hline$S_{2}$ & $30 \times 1 \mathrm{~mm}$ \\
\hline$S_{3}$ & $3.5 \times 1 \mathrm{~mm}$ \\
\hline$n_{1}$ & $4 \times 0.5 \mathrm{~mm}$ \\
\hline$n_{2}$ & $0.5 \times 0.5 \mathrm{~mm}$ \\
\hline
\end{tabular}

Table 1: optimum values for the proposed design.

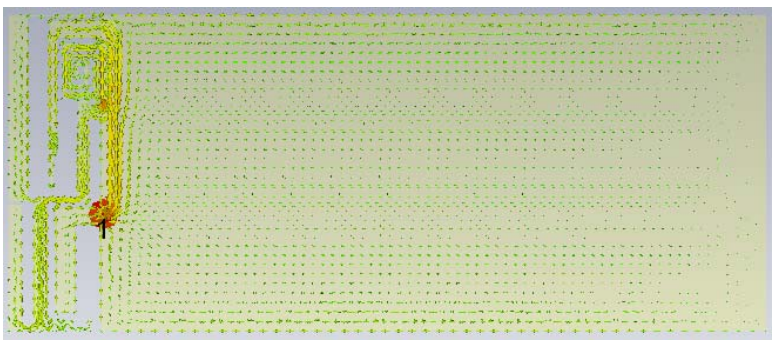

(a) Ref design

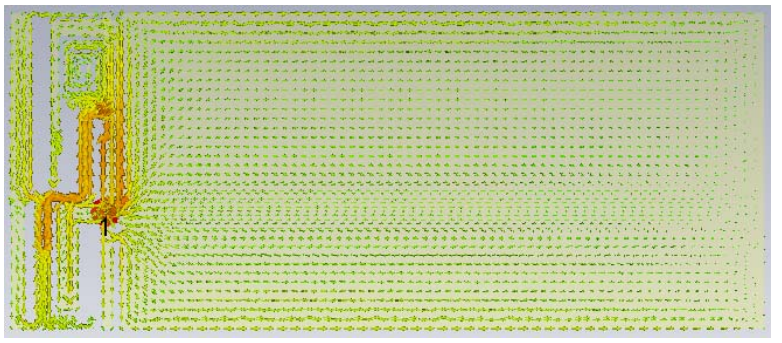

(b) Proposed design

Figure 5: Simulated surface currents at $715 \mathrm{MHz}$ for (a) Ref design and (b) Proposed design.

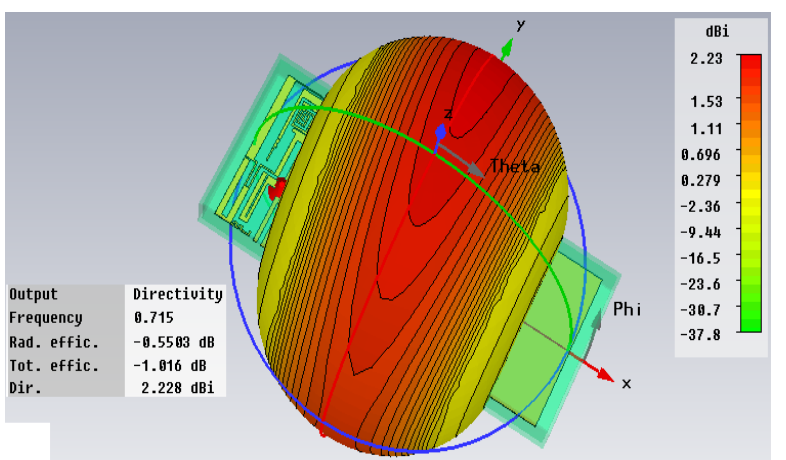

Figure 6: Simulated radiation pattern at $715 \mathrm{MHz}$ for proposed design

\section{CONCLUSION}

In this paper, intelligent slots and notches inserted into the ground plane of a planar monopole antenna have been shown to enhance and tune impedance bandwidth at various standard frequency bands. No optimization to the antenna elements configuration or a change volume was required. A major benefit of the slots and notches is their size which leaves ample space to accommodate other components in the mobile device chassis. Compared to the antenna design without slots and notches, the proposed modifications have increased the bandwidth by an average of $6 \%$. It is now possible to cover the twelve standard operating frequency bands for LTE, GSM, UMTS, WiMAX and WLAN. The proposed technique is very attractive for the new generation of low-profile multi-frequency mobile phone devices.

\section{References}

[1] P. Vainikainen, O. Kivek"as, and I. Kelander, "Resonator-based analysis of the combination of mobile handset antenna and chassis", IEEE Trans on Antens and Propag, Vol. 50, No. 10, 14331444, October 2002.

[2] R. Hossa, and M. E. Bialkowski, "Improvement of compact terminal antenna performance by incorporating open-end slots in ground plane", IEEE Microwave and Wireless Com. Lett., Vol. 14, No. 6, June 2004.

[3] C. Picher, and J. Anguera, "Multiband handset antenna using slots on the ground plane: considerations to facilitate the integration of the feeding transmission line", Progress in Electromagnetics Research C, Vol. 7, 95-109, 2009.

[4] C. Picher, J. Anguera, A. Bujalance, A. Audujar, and C. Puente, "Analysis of a multiband monopole handset antenna combined with slotted ground plane", Microwave and Opt Techn Lett, Vol. 55, No. 1, January 2013.

[5] Z. Chen, Y. L. Ban, J. H. Chen, J. L. W. Li, and Y. J. Wu, "Bandwidth enhancement of LTE/WWAN printed mobile phone antenna using slotted ground structure", Progress in Electromagnetics Research C, Vol. 129, 469-483, 2012.

[6] Jaume Anguera, Ivan Sanz, Josep Mumbru, and Carles Puente, "Multiband handset antenna with paralle excitation of PIFA and slot radiators", IEEE Trans on Antens and Propag, Vol. 58, No. 2, 1433-1444, February 2010. 